\title{
Avoidable waste related to inadequate methods and incomplete reporting of interventions: a systematic review of randomized trials performed in Sub- Saharan Africa
}

Lee Aymar Ndounga Diakou ${ }^{1,2,3^{*}}$, Francine Ntoumi ${ }^{1,4,5}$, Philippe Ravaud ${ }^{2,3,6}$ and Isabelle Boutron ${ }^{2,3,6}$

\begin{abstract}
Background: Randomized controlled trials (RCTs) are needed to improve health care in Sub-Saharan Africa (SSA). However, inadequate methods and incomplete reporting of interventions can prevent the transposition of research in practice which leads waste of research. The aim of this systematic review was to assess the avoidable waste in research related to inadequate methods and incomplete reporting of interventions in RCTs performed in SSA.

Methods: We performed a methodological systematic review of RCTs performed in SSA and published between 1 January 2014 and 31 March 2015. We searched PubMed, the Cochrane library and the African Index Medicus to identify reports. We assessed the risk of bias using the Cochrane Risk of Bias tool, and for each risk of bias item, determined whether easy adjustments with no or minor cost could change the domain to low risk of bias. The reporting of interventions was assessed by using standardized checklists based on the Consolidated Standards for Reporting Trials, and core items of the Template for Intervention Description and Replication. Corresponding authors of reports with incomplete reporting of interventions were contacted to obtain additional information. Data were descriptively analyzed.

Results: Among 121 RCTs selected, 74 (61\%) evaluated pharmacological treatments (PTs), including drugs and nutritional supplements; and 47 (39\%) nonpharmacological treatments (NPTs) (40 participative interventions, 1 surgical procedure, 3 medical devices and 3 therapeutic strategies). Overall, the randomization sequence was adequately generated in 76 reports (62\%) and the intervention allocation concealed in 48 (39\%). The primary outcome was described as blinded in 46 reports (38\%), and incomplete outcome data were adequately addressed in 78 (64\%). Applying easy methodological adjustments with no or minor additional cost to trials with at least one domain at high risk of bias could have reduced the number of domains at high risk for 24 RCTs (19\%). Interventions were completely reported for 73/121 (60\%) RCTs: 51/74 (68\%) of PTs and 22/47 (46\%) of NPTs. Additional information was obtained from corresponding authors for 11/48 reports (22\%).
\end{abstract}

Conclusion: Inadequate methods and incomplete reporting of published SSA RCTs could be improved by easy and inexpensive methodological adjustments and adherence to reporting guidelines.

Keywords: Sub-Saharan Africa, Randomized controlled trials, Risk of bias, Reporting, Research implementation

\footnotetext{
* Correspondence: leeaymar@gmail.com

${ }^{1}$ Fondation Congolaise pour la Recherche Médicale (FCRM), Brazzaville,

République du Congo

${ }^{2}$ INSERM, UMR 1153 Epidemiology and Biostatistics Sorbonne Paris Cité

Center (CRESS), METHODS Team, Paris, France

Full list of author information is available at the end of the article
} 


\section{Background}

Sub-Saharan Africa (SSA) is characterized by extensive morbidity and mortality mainly due to infectious diseases as well as chronic and noncommunicable diseases $[1,2]$. As the standard for establishing the effectiveness of two interventions or more, randomized controlled trials (RCTs) are needed to overcome the global burden of disease and to improve health care in SSA.

Results of RCTs performed in high-income countries (HICs) cannot easily be transposed to SSA because of differences of contexts [3, 4]. In fact, the social and cultural environment, infrastructure organization and availability of facilities differ greatly [5]. For instance, in SSA, people often consult a physician late, frequently use selfmedication and have several comorbidities (malnourishment, anemia, malaria, etc.) and do not always adhere to treatment $[6,7]$.

Recently, Chalmers and colleagues raised an important debate by highlighting that up to $85 \%$ of current research is wasted and that most of this waste is avoidable [8]. For example, a recent study showed that $43 \%$ of RCTs included in Cochrane systematic reviews had at least one domain at high risk of bias; while simple methodological adjustments with no or minor cost could have been applied to reduce this risk [9]. For example, the use of sequentially numbered, opaque, sealed envelopes to conceal the treatment allocation or performing an intention-to-treat analysis are simple low-cost methods that would avoid bias [9]. Similarly, Glasziou and colleagues demonstrated that inadequate reporting of interventions for RCTs was frequently a barrier to the transposition of research results to practice $[10,11]$.

This avoidable waste in research raises an important concern because such RCTs are not consistent with the Declaration of Helsinki which requires that "Medical research involving human subjects must conform to generally accepted scientific principles, be based on a thorough knowledge of the scientific literature (...)" and that "Researchers have a duty to make publicly available the results of their research on human subjects and are accountable for the completeness and accuracy of their reports."

In a first study on the epidemiology of published RCTs performed in SSA, we showed that most RCTs focused on diseases with a high burden in SSA. However, the leadership and funding sources of these trials were mainly from high-income countries (HICs) [12]. The objective of the current study was to assess the avoidable waste in research related to inadequate methods (i.e., those leading to a high risk of bias) and incomplete reporting of interventions for RCTs performed in SSA.

\section{Methods}

This methodological systematic review was conducted and reported according to the Preferred Reporting Items for Systematic reviews and Meta-Analyses Statements (PRISMA) [13]. The checklist items pertain to the content of the review is available in Additional file 1. As the study did not concern human or clinical data, we did not record the protocol on PROSPERO.

\section{Searches}

We performed a methodological systematic review of all RCTs conducted in SSA and published from 1 January 2014 to 31 March 2015. We relied on a sample of RCTs that was used in a previous work which aimed to describe the epidemiology of RCTs in SSA [13]. In brief, we searched for all reports of published RCTs indexed in PubMed, the Cochrane Central Register of Controlled Trials (CENTRAL) and the African Index Medicus (AIM) based on the Cochrane Highly Sensitive Search Strategy for identifying randomized trials [14] combined to a geographic search filter to identify RCTs in Africa [15]. The core search string was varied depending on the database (see Additional file 2). The AIM database was developed by the World Health Organization (WHO) in collaboration with the Association for Health Information and Libraries in Africa (AHILA). It gives access to information published in, or related to Africa and includes about 140 African journals [16]. The search strategy for the AIM database was carried out with the help of the head librarian of the WHO regional office for Africa (WHO-Afro). LAND searched PubMed and CENTRAL.

\section{Study inclusion and exclusion criteria}

We downloaded all retrieved references in Endnote and all duplicates were deleted. First, one of us (LAND) screened all titles and abstracts to identify the relevant studies based on defined eligibility criteria. Another researcher (CL or $\mathrm{RH}$ or $\mathrm{AB}$ ) confirmed the trials' eligibility. If the information was unclear or insufficient in the abstract, the full-text article was systematically retrieved to confirm eligibility. Then, the same researcher (LAND) retrieved all full texts and assessed their eligibility. We included RCTs with at least one center located in SSA. International multicenter trials including both participants from SSA and non-SSA countries were also eligible. We defined an RCT as a clinical study that randomly allocated participants to different interventions: pharmacological treatments (PTs) including drugs or nutritional supplements; and nonpharmacological treatments (NPTs) such as education and training (e.g., exercise program), service delivery, rehabilitation, devices or surgery. We excluded reports of secondary publications of RCTs, phase I/II trials, pilot studies, nonrandomized and pseudo-randomized studies, observational studies, and reports of studies pooling data from more than one RCT. Protocols of RCTs, meeting abstracts, letters, comments and books were also excluded. We did not apply any language restriction for study eligibility. 


\section{Data extraction strategy}

Two review authors independently recorded data by using a standardized data extraction form. Disagreements were resolved by discussion and consensus. We systematically assessed and recorded the following:
1. General characteristics of RCT reports

We recorded the study location, the medical area, study design, type of experimental interventions (PTs or NPTs) and the comparator, and sample size.

Table 1 Definition of the domains of the Risk of Bias tool and the support for judgement according to the Cochrane handbook for systematic reviews of interventions

\begin{tabular}{|c|c|c|c|}
\hline \multirow{2}{*}{$\begin{array}{l}\text { Domains (type } \\
\text { of bias) }\end{array}$} & \multicolumn{3}{|l|}{ Review authors' judgement } \\
\hline & Low risk of bias & High risk of bias & Unclear risk of bias. \\
\hline $\begin{array}{l}\text { Random } \\
\text { sequence } \\
\text { generation } \\
\text { (selection bias) }\end{array}$ & $\begin{array}{l}\text { The investigators describe a random } \\
\text { component in the sequence generation } \\
\text { process such as drawing of lots }\end{array}$ & $\begin{array}{l}\text { The investigators describe a nonrandom } \\
\text { component in the sequence generation } \\
\text { process. Usually, the description would } \\
\text { involve some systematic, nonrandom }\end{array}$ & $\begin{array}{l}\text { Insufficient information about the } \\
\text { sequence generation process to permit } \\
\text { judgement of "low risk" or "high risk" }\end{array}$ \\
\hline
\end{tabular}

Allocation Participants and investigators enrolling concealment (selection bias) participants could not foresee assignment because of the use of, for example, sequentially numbered, opaque, sealed envelopes to conceal allocation involve some systematic, nonrandom approach

Participants or investigators enrolling participants could possibly foresee assignments and thus introduce selection bias, such as allocation based on assignment envelopes used without appropriate safeguards (e.g., if envelopes were unsealed or nonopaque or not sequentially numbered

Blinding of Any one of the following: participants and • No blinding or incomplete blinding, but personnel (performance bias) the review authors judge that the outcome is not likely to be influenced by lack of blinding - Blinding of participants and key study personnel ensured, and unlikely that the blinding could have been broken

Blinding of outcome assessment (detection bias)

Any one of the following:

- No blinding of outcome assessment, but the review authors judge that the outcome measurement is not likely to be influenced by lack of blinding

- Blinding of outcome assessment ensured and unlikely that the blinding could have been broken

Incomplete outcome data (attrition bias)
Any one of the following:

- No missing outcome data

- Reasons for missing outcome data unlikely to be related to true outcome (for survival data, censoring unlikely to be introducing bias)

- Missing outcome data balanced in numbers across intervention groups, with similar reasons for missing data across groups

- For dichotomous outcome data, the proportion of missing outcomes compared with observed event risk not enough to have a clinically relevant impact on the intervention effect estimate - For continuous outcome data, plausible effect size (difference in means or standardized difference in means) among missing outcomes not enough to have a clinically relevant impact on observed effect size

- Missing data have been imputed using appropriate methods.
Any one of the following:

- No blinding or incomplete blinding, and the outcome is likely to be influenced by lack of blinding

- Blinding of key study participants and personnel attempted but likely that the blinding could have been broken, and the outcome is likely to be influenced by lack of blinding

Any one of the following:

- No blinding of outcome assessment, and the outcome measurement is likely to be influenced by lack of blinding - Blinding of outcome assessment, but

likely that the blinding could have been broken, and the outcome measurement is likely to be influenced by lack of blinding

Any one of the following:

- Reason for missing outcome data likely to be related to true outcome, with either imbalance in numbers or reasons for missing data across intervention groups - For dichotomous outcome data, the proportion of missing outcomes compared with observed event risk enough to induce clinically relevant bias in intervention effect estimate

- For continuous outcome data, plausible effect size (difference in means or standardized difference in means) among missing outcomes enough to induce

clinically relevant bias in observed effect size

- "As-treated" analysis done with substantial departure of the intervention received from that assigned at randomization

- Potentially inappropriate application of simple imputation.
Insufficient information to permit judgement of "low risk" or "high risk". This is usually the case if the method of concealment is not described or not described in sufficient detail to allow a definite judgement - for example, if the use of assignment envelopes is described, but it remains unclear whether envelopes were sequentially numbered, opaque and sealed

Any one of the following:

- Insufficient information to permit judgement of "low risk" or "high risk"

- The study did not address this outcome

Any one of the following:

- Insufficient information to permit judgement of "low risk" or "high risk"

- The study did not address this outcome

Any one of the following:

- Insufficient reporting of attrition/ exclusions to permit judgement of "low risk" or "high risk" (e.g., number randomized not stated, no reasons for missing data provided)

- The study did not address this outcome. 
We used the Risk of Bias (RoB) tool developed by the Cochrane Collaboration [17] to assess the following key domains: sequence generation, allocation concealment, blinding of participants, care providers and outcome assessors, and incomplete outcome data. Two researchers (LAND and (CL or RH or AB)) independently assessed the risk of bias and then discussed the assessment to reach consensus. A third assessor (IB) was involved if needed. For each domain, we evaluated whether the risk of bias was high (i.e., may alter the results seriously), low (i.e., if present, unlikely to alter the results seriously), or unclear (i.e., insufficient information reported to permit judgement) [17]. The definition of the domains of the RoB tool and the support for judgement are reported in Table 1 [18].

For each trial with at least one domain at high risk of bias, we identified the methodological problem(s) and determined whether easy adjustments with no or minor cost could change the domains to low risk of bias according to the classification proposed by Yordanov and colleagues [9]. We focused on easy methodological adjustments with no or minor costs because of funding constraints related to research in the context of SSA. Minor cost was defined as $\leq 5 \%$ of the total cost of the trial [9]

3. Completeness of reporting characteristics of health care interventions

To evaluate the completeness of reporting of the interventions, we used a standardized data extraction form based on the Consolidated Standards for Reporting Trials (CONSORT) statement, its extension for NPTs as well as core items of the Template for Intervention Description and Replication (TIDieR) Checklist [19-21]. The data extraction for each type of interventions is reported in Table 2.

We considered an intervention completely reported when the fields listed in Table 2 were reported and when applicable [22]. Then, we systematically emailed the corresponding authors of reports with incomplete reporting of the intervention and asked

Table 2 Extraction fields across different types of health care interventions

\begin{tabular}{|c|c|c|c|c|}
\hline \multirow[t]{2}{*}{ Extraction fields } & \multicolumn{4}{|l|}{ Type of interventions } \\
\hline & $\begin{array}{l}\text { Pharmacological (drugs } \\
\text { and nutritional } \\
\text { supplements) }\end{array}$ & $\begin{array}{l}\text { Nonpharmacological (rehabilitation, } \\
\text { behavioral treatment, education, } \\
\text { psychotherapy) }\end{array}$ & $\begin{array}{l}\text { Surgical procedures and } \\
\text { medical devices (disposal or } \\
\text { implementable) }\end{array}$ & $\begin{array}{l}\text { Other (e.g., } \\
\text { therapeutic } \\
\text { strategies) }\end{array}$ \\
\hline $\begin{array}{l}\text { Setting (location and type of } \\
\text { infrastructure delivering the } \\
\text { intervention) }\end{array}$ & $x$ & $x$ & $x$ & $x$ \\
\hline Dose & $x$ & & & \\
\hline $\begin{array}{l}\text { Mode of administration (e.g., } \\
\text { oral versus intravenous) }\end{array}$ & $x$ & & & \\
\hline Timing & $x$ & & & \\
\hline Duration of treatment & $x$ & & & \\
\hline Treatment adherence & $x$ & $x$ & & \\
\hline $\begin{array}{l}\text { Intervention development } \\
\text { process }\end{array}$ & & $x$ & & \\
\hline $\begin{array}{l}\text { Intervention content } \\
\text { (components) }\end{array}$ & & $x$ & & \\
\hline $\begin{array}{l}\text { Equipment or materials used or } \\
\text { provided (physical or } \\
\text { informational) }\end{array}$ & & $x$ & & $x$ \\
\hline $\begin{array}{l}\text { Mode of implementation (e.g., } \\
\text { individually versus in groups) }\end{array}$ & & $x$ & & \\
\hline $\begin{array}{l}\text { Schedule (frequency or } \\
\text { intensity, timing and duration) }\end{array}$ & & $x$ & & \\
\hline Care provider background & & $x$ & $x$ & $x$ \\
\hline Pre-(operative) care & & & $x$ & $x$ \\
\hline Anesthesia & & & $x$ & \\
\hline $\begin{array}{l}\text { Procedure (sequencing of the } \\
\text { technique) }\end{array}$ & & & $x$ & $x$ \\
\hline Post-(operative) care & & & $x$ & $x$ \\
\hline
\end{tabular}


them to send us any missing details. One reminder was systematically sent after 1 month of no reply.

We concluded no response when any reply was received to that reminder 3 months later.

4. Endorsement of CONSORT by journals

We systematically searched all journal's websites for instructions to authors to check whether it required adherence to the CONSORT statement or to the EQUATOR Website.

\section{Data analysis}

We entered the details of initial and follow-up ratings of reports into a customized Excel database. All analyses involved the use of SAS for Windows 9.3 (SAS Inst., Cary, NC, USA). For each item assessed, and by intervention type, data were summarized descriptively as frequency and percentage or median and interquartile range (IQR). We performed a post hoc analysis, using a chi-square test for categorical data, to assess the link between the endorsement of CONSORT by journals and the completeness of intervention reporting (alpha $=0.05$ ).

\section{Results}

\section{Reports identification}

The screening process is described in Fig. 1. The search identified 1827 reports after removing duplicates. The initial screening excluded 1627 records. For the remaining
200 reports, the full-text articles were retrieved for analysis. We declared 79 reports ineligible because they concerned secondary analyses of primary RCT reports $(81 \%, n=64)$ or were conducted in northern Africa $(19 \%, n=15)$. Overall, 121 reports were included for data extraction. All the selected references are reported in the Additional file 3.

\section{Study characteristics}

General characteristics of the studies are in Table 3. Most RCTs focused on malaria (20\%, $n=25)$, HIV/AIDS $(19 \%, n=24)$, tuberculosis $(3.3 \% ; n=4)$, diarrheal diseases $(2.4 \% ; n=3)$, preterm birth complications $(1.6 \%$; $n$ $=2$ ) and other diseases $(52.2 \%, n=63)$.

The median (IQR) sample size was 346 [160-932]. The study design was mainly parallel individual groups $(80 \%, n$ = 97) and cluster RCTs $(15 \%, n=19)$. Interventions evaluated both PTs $(61 \%, n=74)$ and NPTs $(39 \%, n=47)$, including participative interventions $(85 \%, n=40)$, surgical procedures $(2 \%, n=1)$, implementable or disposal devices $(2 \%, n=3)$ and therapeutic strategies $(2 \%, n=3)$. The comparator interventions were active interventions (35\%, $n=43)$, usual care $(26 \%, n=32)$ or placebo $(19 \%, n=24)$.

\section{Inadequate methods and risk of bias in RCTs}

The risk of bias in reports of RCTs is in Fig. 2. Overall, 92/121 trials (76\%) had at least one domain at high risk of bias. Included RCTs were at high risk

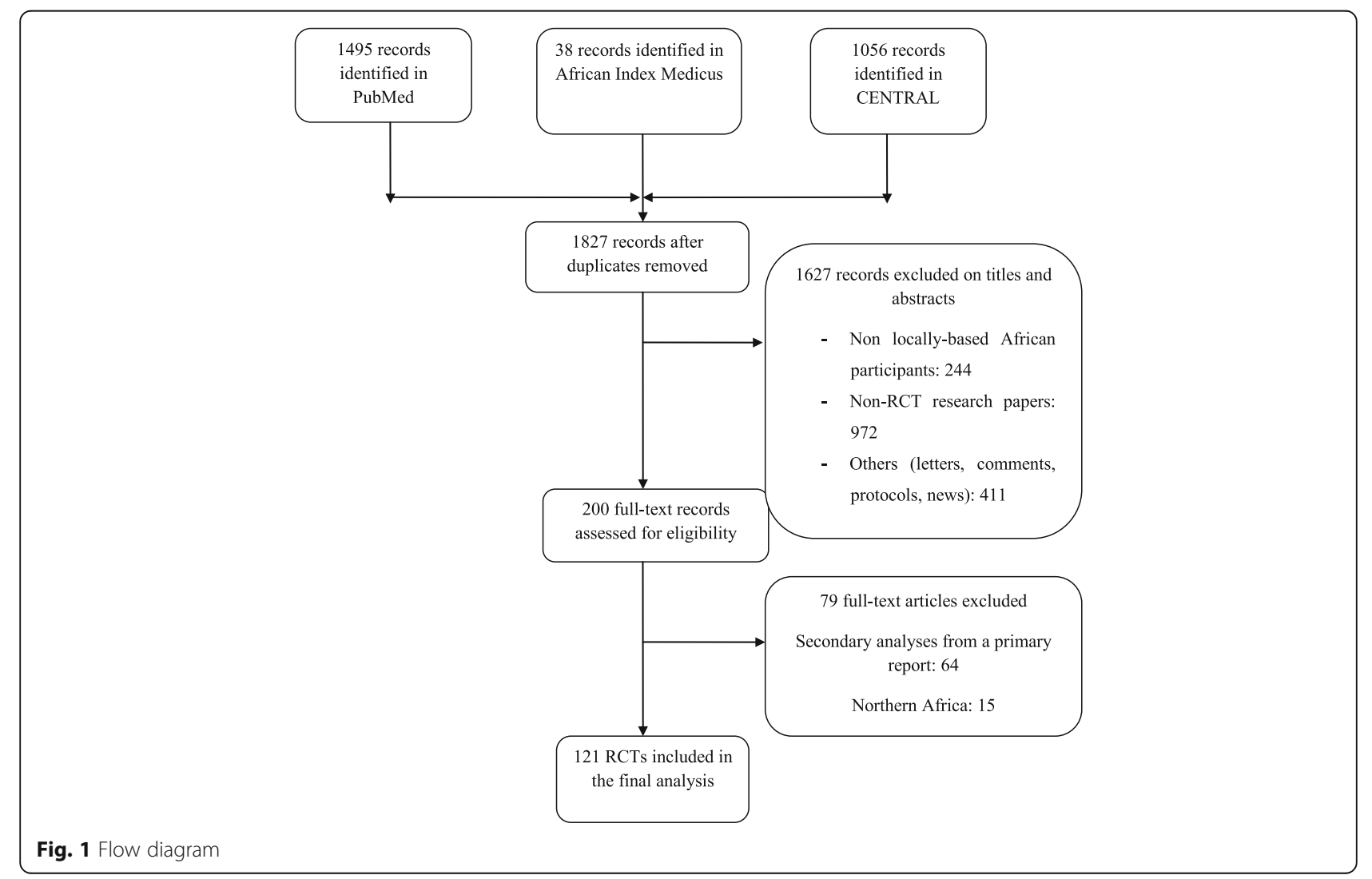


Table 3 General characteristics of the included randomized controlled trial reports

\begin{tabular}{|c|c|}
\hline Characteristics & $N=121$ \\
\hline \multicolumn{2}{|l|}{ Trial location } \\
\hline Sub-Saharan countries only & $104(85.9)$ \\
\hline - South Africa & $20(19.2)$ \\
\hline - Nigeria & $12(11.5)$ \\
\hline - Tanzania & $10(9.6)$ \\
\hline - Kenya & $8(7.6)$ \\
\hline - Uganda & $8(7.6)$ \\
\hline - Malawi & $6(5.7)$ \\
\hline - Rwanda & $4(3.8)$ \\
\hline - Ethiopia & $3(2.8)$ \\
\hline Several Sub-Saharan countries & $5(4.1)$ \\
\hline $\begin{array}{l}\text { Sub-Saharan African countries and high-income coun- } \\
\text { tries (HICs) or other countries (not HICs) }\end{array}$ & $12(8.9)$ \\
\hline \multicolumn{2}{|l|}{ Medical area } \\
\hline Malaria & $25(20.6)$ \\
\hline HIV/AIDS & $24(19.9)$ \\
\hline Tuberculosis & $4(3.3)$ \\
\hline Diarrheal diseases & $3(2.4)$ \\
\hline Preterm birth complications & $2(1.6)$ \\
\hline Other diseases & $63(52.2)$ \\
\hline \multicolumn{2}{|l|}{ Study design } \\
\hline Parallel groups & $97(80.1)$ \\
\hline Clusters & 19 (15.8) \\
\hline Factorial design & $3(2.4)$ \\
\hline Cross-over & $2(1.7)$ \\
\hline \multicolumn{2}{|l|}{ Experimental intervention } \\
\hline Pharmacological (drugs and nutritional supplements) & $74(61.1)$ \\
\hline Nonpharmacological & $47(38.9)$ \\
\hline - Participative interventions & $40(85.1)$ \\
\hline - Devices & $3(6.3)$ \\
\hline - Surgical procedures & $1(2.3)$ \\
\hline - Therapeutic strategies & $3(6.3)$ \\
\hline \multicolumn{2}{|l|}{ Comparator } \\
\hline Active treatment & $43(35.5)$ \\
\hline Usual care & $32(26.4)$ \\
\hline Placebo & $24(19.9)$ \\
\hline Other & $22(18.2)$ \\
\hline Sample size (median [IQR]) & $\begin{array}{l}346[160- \\
932]\end{array}$ \\
\hline
\end{tabular}

Data are number. (\%) unless indicated. IQR interquartile range

of bias for 5 (4\%) for generation of randomization sequence, $10(8 \%)$ for allocation concealment, 87 (71\%) for both blinding of participants and personnel, and $61(50 \%)$ for blinding of outcome assessor. Incomplete outcome data were inadequately addressed in 16 (13\%).

Applying easy methodological adjustments with no or minor additional cost to trials with at least one domain at high risk of bias could have reduced the number of domains at high risk for 24 trials (19\%). These adjustments could correct all trials at high risk of bias for sequence generation, allocation concealment and incomplete outcome data especially. None of the RCTs at high risk of bias for blinding status of participants, personnel or outcome assessors could be corrected because this would involve a medium or difficult adjustment with major cost [9]. All methodological adjustments applied to each identified problem according to the domain of risk of bias are described in Table 4.

\section{Completeness of the intervention reporting}

Reporting of each intervention item for included RCTs is described in Fig. 3. The information needed was completely reported in $60 \%(n=73 / 121)$ of the articles; $68 \%$ $(n=51 / 74)$ of PTs and $46 \%(n=22 / 47)$ of NPTs. None of the RCTs evaluating surgical procedures $(n=1)$, medical devices $(n=3)$, or therapeutic strategies $(n=3)$ was completely reported. Request for additional information for reports with incomplete reporting provided data for 11/ 48 RCTs (22\%).

Overall, we found that $68 \%(n=82 / 121)$ of RCTs were published in a journal requiring adherence to CONSORT. Reporting was complete in $62 \%(n=51 / 82)$ of RCTs published in journals requiring adherence to the guidelines versus $51 \%(n=20 / 39)$ when published in a journal not requiring CONSORT adherence; $\mathrm{chi}^{2}=1,29 ; P=0.25$.

\section{Discussion}

We evaluated the avoidable waste in research related to inadequate methods and incomplete reporting of interventions in reports of RCTs performed in SSA and published over 1 year. Applying easy and methodological adjustments with no or minor cost could have limited the number of domains at high risk of bias for $19 \%$ of trials with at least one domain at high risk. Moreover, additional information requested of the corresponding authors of reports with incomplete descriptions overall improved the completeness of trial reporting from $60 \%$ to $69 \%$.

\section{Comparison with other studies}

Most studies evaluating the reporting and methods of RCTs conducted in SSA focused on specific diseases, and to our knowledge, none evaluated the impact of methodological adjustments [23-26]. In a review of 76 RCTs of HIV/AIDS conducted in Africa, the generation of the randomization sequence and the allocation concealment were judged 

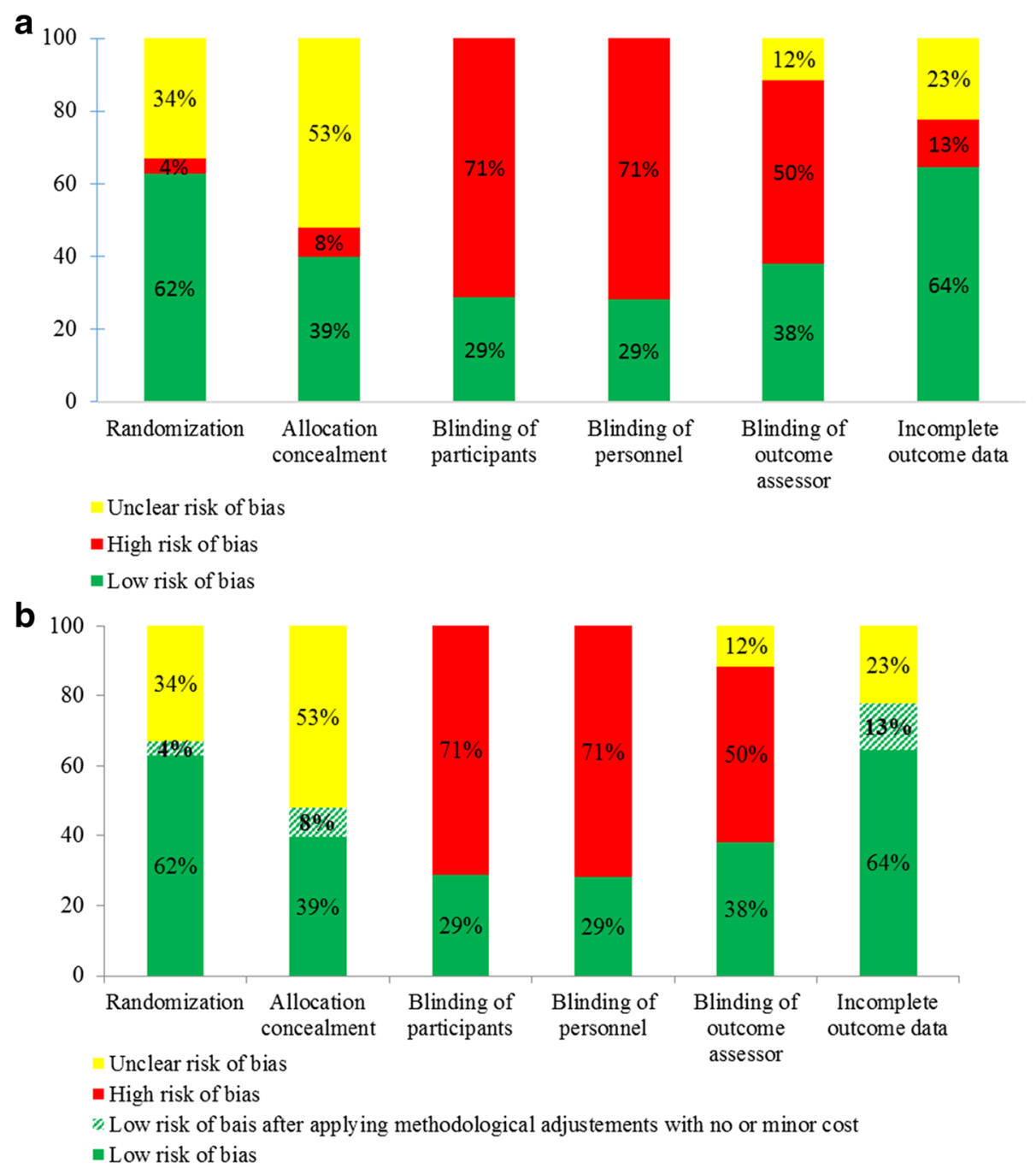

Fig. 2 Risk of bias in 121 randomized controlled trials (RCTs) performed in Sub-Saharan Africa. Initial risk of bias (a) and risk of bias after applying easy methodological adjustments with no or minor additional cost (b). Vertical bars represent domains assessed according the Risk of Bias tool of the Cochrane Collaboration

Table 4 Problems identified in randomized controlled trials confirmed to be at high risk of bias and methodological adjustments with no or minor cost applied

\begin{tabular}{|c|c|c|c|c|}
\hline Domains & Type of problem in original trial report & $\begin{array}{l}N= \\
121 \\
\text { No. } \\
(\%)\end{array}$ & Methodological adjustment & Cost \\
\hline $\begin{array}{l}\text { Generation of } \\
\text { randomization } \\
\text { sequence }\end{array}$ & $\begin{array}{l}\text { Inappropriate randomization methods including sequence } \\
\text { generated by some rule based on date/day of admission or } \\
\text { on hospital or clinic record number }\end{array}$ & $5(4)$ & $\begin{array}{l}\text { Referring to a random number table; } \\
\text { Using a computer random-number generator } \\
\text { Coin tossing Shuffling cards or envelopes } \\
\text { Throwing dice } \\
\text { Drawing of lots }\end{array}$ & $\begin{array}{l}\text { No } \\
\text { cost }\end{array}$ \\
\hline $\begin{array}{l}\text { Allocation } \\
\text { concealment }\end{array}$ & $\begin{array}{l}\text { No explicitly unconcealed procedure or unsealed or } \\
\text { nonopaque or not sequentially numbered envelopes }\end{array}$ & $10(8)$ & $\begin{array}{l}\text { Central allocation (including telephone, web-based } \\
\text { and pharmacy-controlled randomization) or sequen- } \\
\text { tially numbered, opaque, sealed envelopes }\end{array}$ & Minor \\
\hline \multirow[t]{2}{*}{$\begin{array}{l}\text { Incomplete } \\
\text { outcome data }\end{array}$} & Exclusion of patients from the analysis & $\begin{array}{l}14 \\
(11)\end{array}$ & Intention-to-treat analysis & $\begin{array}{l}\text { No } \\
\text { cost }\end{array}$ \\
\hline & $\begin{array}{l}\text { Intention-to-treat analysis but inadequate missing data } \\
\text { imputation }\end{array}$ & $2(1)$ & $\begin{array}{l}\text { Intention-to-treat analysis with a multiple imputation } \\
\text { method }\end{array}$ & Minor \\
\hline
\end{tabular}


a

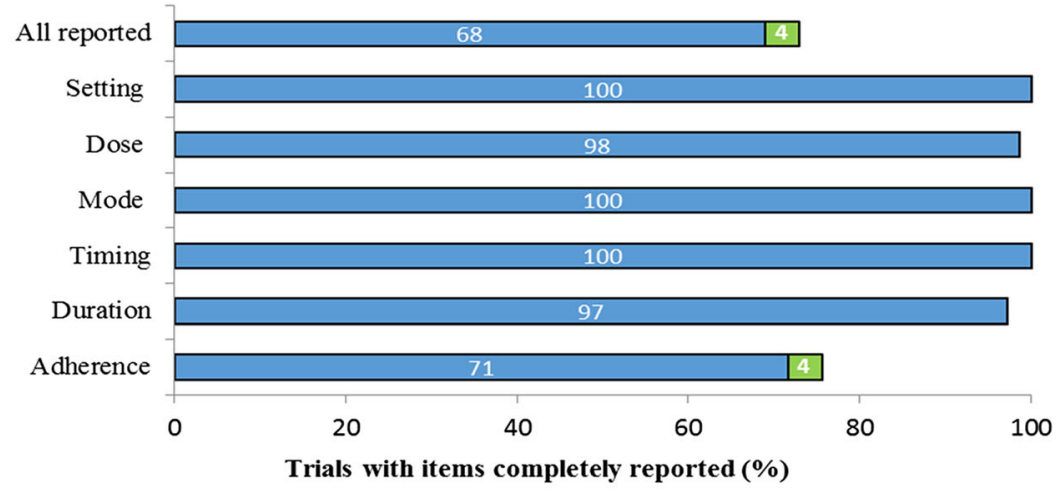

b

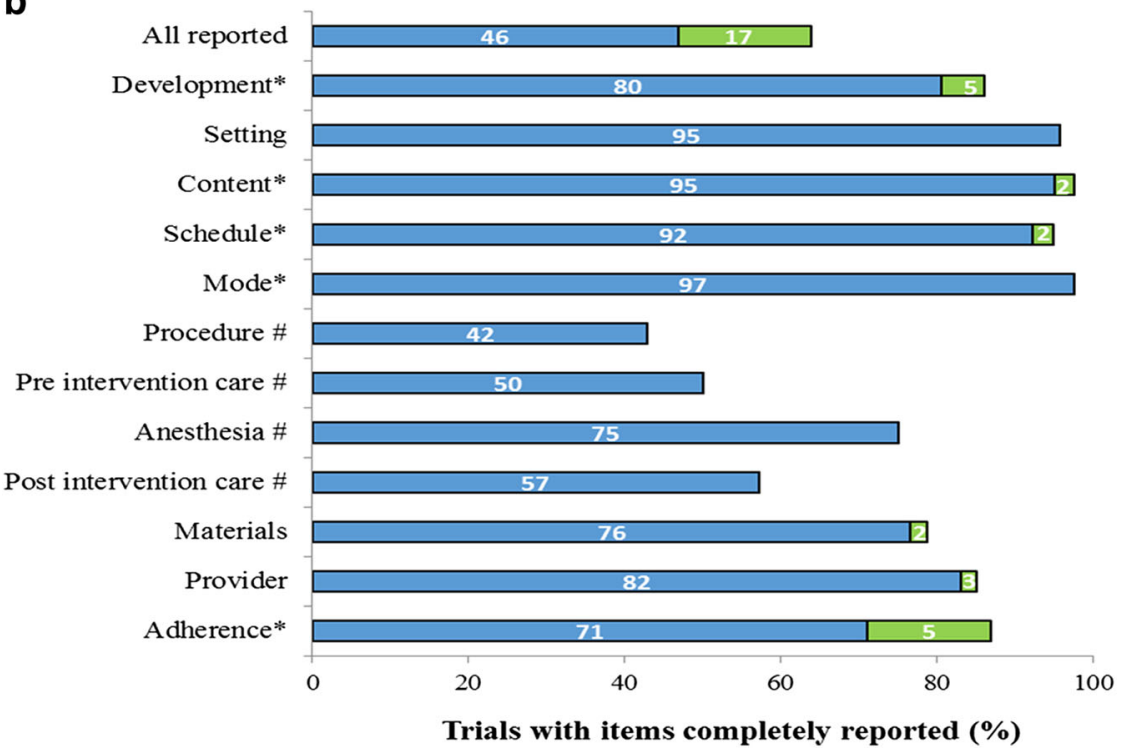

Fig. 3 Reporting of interventions evaluated in randomized controlled trials (RCTs) performed in Sub-Saharan African ( $n=121)$. Pharmacological treatments, $n=74$ RCTs (a) and nonpharmacological treatments, $n=47 \mathrm{RCTs}(\mathbf{b})$. For both type of interventions, the percentage of interventions rated as completely reported for each item in initial trial reports is illustrated in blue. The additional percentage after author reply is in green. ${ }^{*}$ ) items assessed only for participative interventions. (\#) items assessed only for devices or surgical procedures

adequate for only $41 \%$ and $51 \%$ of trials respectively, and $33 \%$ of trials reported blinded outcome assessors [24]. Another descriptive analysis of 60 African RCTs of malaria reported adequate generation of random sequence and allocation concealment for $58 \%$ and $23 \%$ respectively, with participants or providers adequately blinded in $38 \%$ and loss to follow-up accounted for in $81 \%$ of reports [26]. Even though results vary to some extent among studies, these reviews raised substantial issues related to inadequate methods in SSA trials.

Furthermore, the concern of poor trial reporting remains a long-told story [27, 28]. Although we did not find any study specifically focusing on how completely interventions are described in reports of SSA RCTs, the inadequate description of interventions in trial reports has been pointed out for many years $[9,11,12]$.
In their early analysis, Glasziou and colleagues concluded that poor reporting was an important barrier to the replication of interventions in clinical practice [9]. Recently, Hoffmann and colleagues showed inadequate descriptions for more than $60 \%$ of NPTs [29]. In another cross-sectional study of published trials, Schröter and colleagues highlighted that the most poorly described aspects of interventions in trial reports were the actual procedures involved, including the sequencing of the technique (what happened, how and when) and the physical or informational materials used [30]. These results were confirmed in our analysis of trials conducted in SSA. To increase research value, we must develop specific tools and support accessibility to researchers based in SSA. Furthermore, we need to work on specific solutions and tools to decrease this waste in SSA. 


\section{Perspectives and implications}

The CONSORT statement was developed to improve the reporting of RCTs [19]. However, even if the quality of reporting for RCTs has significantly increased since the publication and the endorsement of CONSORT by many journals [31-33], the reporting of interventions remains insufficient, particularly for NPTs [34-36]. To address this issue, the extension of the CONSORT statement for NPTs and the TIDieR Checklist were developed to improve the implementation of interventions in clinical practice $[20,21]$. Nevertheless, adherence to these reporting guidelines must be improved at different levels, first by helping authors adherence to the CONSORT statement when writing the first draft of the manuscript. Second, editors should require and enforce adherence to the CONSORT statement. Third, the completeness of reporting should be monitored at the peer-review process by the submission of checklists or other types of interventions such as the development of tools to combine the CONSORT checklist and its extensions [37].

The implications of this work are important for SSA because of the small number of RCTs performed in this part of the world [38], and the shortage of research resources. For this reason, waste must be addressed. In accordance previous works $[9,39]$, our results highlight that waste in RCTs in SSA could be avoided with simple and inexpensive methodological adjustments as well as a better reporting of interventions. Investigators should be informed of the feasibility of these adjustments and reporting guidelines when planning their trials and drafting their reports to limit the number of flaws in trial methods and poor descriptions of interventions at an early stage $[10,12,40]$. The Enhancing the QUAlity and Transparency Of health Research (EQUATOR) network is an international initiative created to improve the reliability and value of published health research literature by promoting transparent and accurate reporting and wider use of robust reporting guidelines (http://www.equator-network.org/). In our study, articles journals recommending reporting guidelines in their instructions to authors have a better description of interventions than those that did not recommend any reporting guidelines.

\section{Limitations}

This study has limitations. First, our results are based on a sample of published RCTs over 1 year, which could limit generalization. Although our search strategy was large, we cannot ensure that we identified all published RCTs performed in SSA. Second, the assessment of methods and reporting quality relies on what was reported in the published RCT reports, and a gap could exist between what was reported and what was done.

\section{Conclusion}

Inadequate methods and incomplete reporting of published RCTs performed in SSA could be improved by easy and inexpensive methodological adjustments and adherence to reporting guidelines.

\section{Additional files}

Additional file 1: PRISMA Checklist. (DOC $64 \mathrm{~kb}$ )

Additional file 2: Search strategy for randomized controlled trials' (RCTs) reports. (DOC $26 \mathrm{~kb}$ )

Additional file 3: References for the selected randomized controlled trials' (RCTs) reports. (DOC $128 \mathrm{~kb}$ )

\section{Abbreviations}

AHILA: Association for Health Information and Libraries in Africa; AIM: African Index Medicus; CONSORT: Consolidated Standards of Reporting Trials; EQUATOR: Enhancing the QUAlity and Transparency Of health Research; HICs: High-income countries; HIV/AIDS: Human immunodeficiency virus/ acquired immunodeficiency syndrome; IQR: Interquartile range;

NPTs: Nonpharmacological treatments; PTs: Pharmacological treatments; RCT: Randomized controlled trial; RoB: Risk of bias; SSA: Sub-Saharan Africa; TIDieR: Template for Intervention Description and Replication; WHO: World Health Organization

\section{Acknowledgements}

We thank all the corresponding authors for additional data provided. We also thank Clément Lazarus, Romana Haneef and Aïda Bafeta (all from Centre d'Épidémiologie Clinique, Hôpital Hôtel Dieu, Assistance Publique des Hôpitaux de Paris, Paris) who participated in the confirmation of the report's eligibility and data extraction; as well as Laura Smales (BioMedEditing, Toronto, Canada) for editing this manuscript.

\section{Funding}

LAND received a training grant on implementation research (Tims ID: B40091) from the Special Program for Research and Training in Tropical Diseases, World Health Organization (TDR-WHO).

\section{Availability of supporting data}

All data generated or analyzed during this study are included in this published article (and its supplementary information files).

\section{Authors' contributions}

IB, LAND, FN and PR designed the study. LAND collected and analyzed the data. IB, LAND, FN and PR interpreted the data and IB. LAND wrote the draft. FN helped in obtaining research funding. FN and PR critically reviewed the manuscript for intellectual content. All authors read and approved the final manuscript.

\section{Competing interests}

PR is director of the French Cochrane Center and the French Equator Centre. $\mathrm{IB}$ is deputy director of the French Equator Centre, co-convenor of the Cochrane Bias Methods Group and senior editor of Trials. All authors declare no financial relationships with any organizations that could appear to have influenced the submitted work.

Consent for publication

Not applicable

Ethics approval and consent to participate Not applicable

\section{Publisher's Note}

Springer Nature remains neutral with regard to jurisdictional claims in published maps and institutional affiliations. 


\section{Author details}

${ }^{1}$ Fondation Congolaise pour la Recherche Médicale (FCRM), Brazzaville, République du Congo. ${ }^{2}$ INSERM, UMR 1153 Epidemiology and Biostatistics Sorbonne Paris Cité Center (CRESS), METHODS Team, Paris, France. ${ }^{3}$ Paris Descartes University, Paris, France. ${ }^{4}$ Marien Ngouabi University, Brazzaville, Democratic Republic of the Congo. ${ }^{5}$ Institute for Tropical Medicine, University of Tubingen, Tubingen, Germany. ${ }^{6}$ Centre d'Épidémiologie Clinique, Hôpital Hôtel Dieu, Assistance Publique des Hôpitaux de Paris, Paris, France.

Received: 7 December 2016 Accepted: 17 May 2017 Published online: 05 July 2017

\section{References}

1. Naghavi $M$, Wang $H$, Lozano $R$, et al. Global, regional, and national age-sex specific all-cause and cause-specific mortality for 240 causes of death, 19902013: a systematic analysis for the Global Burden of Disease Study 2013. Lancet. 2015;385(9963):117-71.

2. Mensah GA, Roth GA, Sampson UK, Moran AE, Feigin VL, Forouzanfar MH, Naghavi M, Murray CJ, GBD 2013 Mortality and Causes of Death collaborators. Mortality from cardiovascular diseases in sub-Saharan Africa, 1990-2013: a systematic analysis of data from the Global Burden of Disease Study 2013. Cardiovasc J Afr. 2015;26(2 Suppl 1):S6-10.

3. Rothwell PM. External validity of randomised controlled trials: "to whom do the results of this trial apply?". Lancet. 2005;365(9453):82-93.

4. Burchett HE, Dobrow MJ, Lavis JN, Mayhew SH. The applicability and transferability of public health research from one setting to another: a survey of maternal health researchers. Glob Health Promot. 2013;20(1):1624. doi:10.1177/1757975913476904.

5. Garner P, Kale R, Dickson R, Dans T, Salinas R. Getting research findings into practice: implementing research findings in developing countries. BMJ. 1998;317(7157):531-5.

6. Anglaret X, Scott CA, Walensky RP, Ouattara E, Losina E, Moh R, Becker JE, Uhler L, Danel C, Messou E, Eholié S, Freedberg KA. Could early antiretroviral therapy entail more risks than benefits in sub-Saharan African HIV-infected adults? A model-based analysis. Antivir Ther. 2013;18(1):45-55. doi:10.3851/ IMP2231. Epub 2012 Jul 18.

7. Seyler C, Adjé-Touré C, Messou E, Dakoury-Dogbo N, Rouet F, Gabillard D, Nolan M, Toure S, Anglaret X. Impact of genotypic drug resistance mutations on clinical and immunological outcomes in HIV-infected adults on HAART in West Africa. AIDS. 2007;21(9):1157-64.

8. Chalmers I, Glasziou P. Avoidable waste in the production and reporting of research evidence. Lancet. 2009;374(9683):86-9. doi:10.1016/S01406736(09)60329-9. Epub 2009 Jun 12.

9. Yordanov Y, Dechartres A, Porcher R, Boutron I, Altman DG, Ravaud P. Avoidable waste of research related to inadequate methods in clinical trials. BMJ. 2015;350:h809.

10. Glasziou P, Meats E, Heneghan C, Shepperd S. What is missing from descriptions of treatment in trials and reviews? BMJ. 2008;336(7659):1472-4.

11. Glasziou P, Altman DG, Bossuyt P, Boutron I, Clarke M, Julious S, Michie S, Moher D, Wager E. Reducing waste from incomplete or unusable reports of biomedical research. Lancet. 2014;383(9913):267-76.

12. Ndounga Diakou LA, Francine Ntoumi, Philippe Ravaud, Isabelle Boutron. Published randomized trials performed in Sub-Saharan Africa focus on high burden diseases but are frequently funded and led by high income countries. J Clin Epidemiol. 2016. doi:10.1016/j.jclinepi.2016.10.008.

13. Moher D, Liberati A, Tetzlaff J, Altman DG, PRISMA Group. Preferred reporting items for systematic reviews and meta-analyses: the PRISMA statement. PLoS Med. 2009;6(7):e1000097. doi:10.1371/journal.pmed. 1000097. Epub 2009 Jul 21.

14. Glanville JM, Lefebvre C, Miles JN, Camosso-Stefinovic J. How to identify randomized controlled trials in MEDLINE: ten years on. J Med Libr Assoc. 2006;94(2):130-6.

15. Pienaar E, Grobler L, Busgeeth K, Eisinga A, Siegfried N. Developing a geographic search filter to identify randomized controlled trials in Africa: finding the optimal balance between sensitivity and precision. Health Info Libr J. 2011;28(3):210-5.

16. Atani M, Kabore MP. African Index Medicus: improving access to African health information. SA Fam Pract. 2007;49(2):4-7.

17. Higgins JP, Altman DG, Gøtzsche PC, Jüni P, Moher D, Oxman AD, Savovic J, Schulz KF, Weeks L, Sterne JA, Cochrane Bias Methods Group, Cochrane
Statistical Methods Group. The Cochrane Collaboration's tool for assessing risk of bias in randomized trials. BMJ. 2011;343:d5928.

18. Higgins JPT, Green S (editors). Cochrane Handbook for Systematic Reviews of Interventions Version 5.0.0 [updated February 2008]. The Cochrane Collaboration; 2008. Available from www.cochrane-handbook.org.

19. Moher D, Hopewell S, Schulz KF, Montori V, Gøtzsche PC, Devereaux PJ, Elbourne D, Egger M, Altman DG. CONSORT 2010 explanation and elaboration: updated guidelines for reporting parallel group randomised trials. BMJ. 2010;340:C869.

20. Boutron I, Moher D, Altman DG, Schulz KF, Ravaud P, CONSORT Group. Extending the CONSORT statement to randomized trials of nonpharmacologic treatment: explanation and elaboration. Ann Intern Med. 2008;148(4):295-309.

21. Hoffmann TC, Glasziou PP, Boutron I, Milne R, Perera R, Moher D, Altman DG, et al. Better reporting of interventions: template for intervention description and replication (TIDieR) checklist and guide. BMJ. 2014;348:g1687.

22. Craig P, Dieppe P, Macintyre S, Michie S, Nazareth I, Petticrew M, Medical Research Council Guidance. Developing and evaluating complex interventions: the new Medical Research Council guidance. BMJ. 2008;337:a1655.

23. Isaakidis $P$, loannidis JPA. Evaluation of cluster randomized controlled trials in Sub-Saharan Africa. Am J Epidemiol. 2003;158:921-6.

24. Siegfried N, Clarke M, Volmink J, Van der Merwe L. African HIV/AIDS trials are more likely to report adequate allocation concealment and random generation than North American trials. PLoS One. 2008;3(10):e3491.

25. Zani B, Pienaar ED, Oliver J, Siegfried N. Randomized controlled trials of HIV/ AIDS prevention and treatment in Africa: results from the Cochrane HIV/ AIDS Specialized Register. PLoS One. 2011;6(12):e28759. doi:10.1371/journal. pone.0028759.

26. Lutje V, Gerritsen A, Siegfried N. Randomized controlled trials of malaria intervention trials in Africa, 1948 to 2007: a descriptive analysis. Malar J. 2011;10:61.

27. Hopewell S, Dutton S, Yu LM, Chan AW, Altman DG. The quality of reports of randomised trials in 2000 and 2006: comparative study of articles indexed in PubMed. BMJ. 2010;340:C723.

28. Dechartres A, Charles P, Hopewell S, Ravaud P, Altman DG. Reviews assessing the quality or the reporting of randomized controlled trials are increasing over time but raised questions about how quality is assessed. J Clin Epidemiol. 2011;64(2):136-44. doi:10.1016/j.jclinepi.2010.04.015.

29. Hoffmann TC, Erueti C, Glasziou PP. Poor description of nonpharmacological interventions: analysis of consecutive sample of randomized trials. BMJ. 2013;347:f3755.

30. Schroter S, Glasziou P, Heneghan C. Quality of descriptions of treatments: a review of published randomised controlled trials. BMJ Open. 2012;2:6.

31. Plint AC, Moher D, Morrison A, Schulz K, Altman DG, Hill C, Gaboury I. Does the CONSORT checklist improve the quality of reports of randomised controlled trials? A systematic review. Med J Aust. 2006;185(5):263-7.

32. Turner L, Shamseer L, Altman DG, Weeks L, Peters J, Kober T, Dias S, Schulz KF, Plint AC, Moher D. Consolidated standards of reporting trials (CONSORT) and the completeness of reporting of randomised controlled trials (RCTs) published in medical journals. Cochrane Database Syst Rev. 2012;11:MR000030.

33. To MJ, Jones J, Emara M, Jadad AR. Are reports of randomized controlled trials improving over time? A systematic review of 284 articles published in high-impact general and specialized medical journals. PLoS One. 2013;8(12):e84779.

34. Hopewell S, Altman DG, Moher D, Schulz KF. Endorsement of the CONSORT Statement by high impact factor medical journals: a survey of journal editors and journal "Instructions to Authors.". Trials. 2008;9:20.

35. Hoffmann T, English T, Glasziou P. Reporting of interventions in randomised trials: an audit of journal instructions to authors. Trials. 2014;15:20.

36. Nagendran M, Harding D, Teo W, Camm C, Maruthappu M, McCulloch P, Hopewell S. Poor adherence of randomised trials in surgery to CONSORT guidelines for non-pharmacological treatments (NPT): a cross-sectional study. BMJ Open. 2013;3(12):e003898.

37. Barnes C, Boutron I, Giraudeau B, Porcher R, Altman DG, Ravaud P. Impact of an online writing aid tool for writing a randomized trial report: the COBWEB (Consort-based WEB tool) randomized controlled trial. BMC Med. 2015;13:221.

38. Ahmad N, Boutron I, Dechartres A, Durieux P, Ravaud P. Geographical representativeness of published and ongoing randomized controlled trials. 
The example of: Tobacco consumption and HIV infection. PLoS One. 2011; 6(2):e16878. doi:10.1371/journal.pone.0016878.

39. Ioannidis JP, Greenland S, Hlatky MA, Khoury MJ, Macleod MR, Moher D, Schulz KF, Tibshirani R. Increasing value and reducing waste in research design, conduct, and analysis. Lancet. 2014;383(9912):166-75.

40. Cook A, Douet L, Boutron I. Descriptions of non-pharmacological interventions in clinical trials. BMJ. 2013;347:f5212. doi:10.1136/bmj.f5212.

Submit your next manuscript to BioMed Central and we will help you at every step:

- We accept pre-submission inquiries

- Our selector tool helps you to find the most relevant journal

- We provide round the clock customer support

- Convenient online submission

- Thorough peer review

- Inclusion in PubMed and all major indexing services

- Maximum visibility for your research

Submit your manuscript at www.biomedcentral.com/submit 